\title{
The Functional Preparedness Of Football Players With Various Ability
}

\author{
Dao Chanh Thuc ${ }^{\star, \dagger}$ \\ Physical Education Department, An Giang University, VIET NAM
}

DOI: https://doi.org/10.15520/ijmhs.v9i4.2536

Accepted 1 Apl 2019; Received 1 Mar 2019; Publish Online 25 Apl

2019

Reviewed By: Dr

Daniel V.

Department: Medical

\begin{abstract}
This study on the functional readiness of football players in the different game roles of the teams of Vietnam's first and second championships is revealed. The criteria for the readiness of football players are indicators such as maximum oxygen consumption and physical performance.

Functional status of the players is determined in the research laboratory of HCM State Physical Culture Academy. The difference in the structure of the functional readiness of the players with different abilities of different playing roles (goalkeeper, center and wing, central midfield and wing and attack) is revealed.
\end{abstract}

Key words: football players-playing role-functional readiness-VO2max-PWC170

\section{INTRODUCTION}

Modern training management cannot be successful without objective data on the performance of the athlete's body (Tyulenkov, 2007). In situ sports, long-term adap-tation reactions are formed only as a basis for the emer-gency adaptation of athlete creatures to the conditions of a particular game, along with stability. determinations of basic adaptive reactions, determining their wide variability (Platonov, 1988). A large amount of competition in football requires maximum mobilization of the physiological functions of the body. Moreover, as noted by S.Yu. Tulenkov (2007), the issue of assessing adaptive responses is one of the conditions to avoid disruption of adaptation. The crite-ria for the readiness of football players are indicators such as maximum oxygen consumption (VO2max), physical perfor-mance (PWC170) and other indicators (Shamardin, 2012). A lot of work has been devoted to determining the level of IPC indicators and physical work capacity as the criteria for the preparation of function of athletes (Stroyer et al., 2004; Tamlin, 2001). Therefore, according to some experts, reliable VO2max values characterize athletes' physical performance (Pertsukhov A, et al, 2018). It is determined that between the VO2max value and the sporting result, especially in circulating sports, there is a highly reliable correlation. In return, during the training process, VO2max of football players plays a role as one of the criteria to describe

* Corresponding author.

$\dagger$ Email: thuchus@gmail.com. the overall functional status and their adaptation index with training and competition in Different stages of the one-year training cycle (Pertsukhov A, et al, 2018). According to other experts (Shamardin, 2012), the value of VO2max is an indispensable indicator of the efficiency of oxygen transport system and bioenergy index of aerobic ability. Studies by Russian experts (Ordzhonikidze et al., 2007) show a significant correlation between VO2max scores and the distance that players pass during the match. Based on the results of similar studies, a high correlation has been established between VO2max and the distribution of team positions in the Southeast Asian Championship. According to different authors (Helgerud et al., 2002), the average value of VO2max in highly skilled footballers fluctuates in a fairly wide range, from $48.6 \mathrm{ml} / \mathrm{min} \bullet \mathrm{kg}$ - 1 to $77 \mathrm{ml} / \operatorname{min~kg-1}$.

It has long been known that VO2max indicators in the one-year training cycle tend to change, depending on the stage of preparation and the state of participation in the sports form of the player (Shamardin, 2012) . Some experts believe that the maximum level of oxygen consumption is subject to growth in the season, with the release of it to the maximum value to the end (Casajus, 2001). Therefore, the increase level of $\mathrm{VO} 2 \mathrm{max}$ digits is determined primarily by the initial level of VO2max, the mode and orientation of the training process (Pertsukhov A, et al, 2018). Depending on this, the increase of VO2max can reach $40 \%$. However, for well-trained elite class athletes, fluctuations in VO2max values mainly do not exceed $15 \%$. However, in many cases, teams are experiencing VO2max decline at the end of the season (Drust et al., 2000). The difference is described, obvi- 
ously, because some teams end the season in serious physical fatigue, deciding the decline in athlete's physiological parameters. In addition to the maximum oxygen consumption (VO2max), the criteria for functional fitness of players are physical performance (PWC170) (Pertsukhov A, et al, 2018).

The determination of physical performance through PWC170 testing is mainly due to the fact that the increase in heart rate in muscle work is directly proportional to its intensity (Pertsukhov A, et al, 2018). However, the linear part of the curve, which characterizes the dependence of this heart rate on the working intensity, ends at a heart rate of nearly 170 beats per minute. This explains why this heart rate is chosen for PWC170 (Tyulenkov, 2007). The model indicators of physical performance of players are highly qualified according to data from different authors (Ordzhonikidze, Pavlov, 2008) ranging from 18.8 to $22.5 \mathrm{~kg}$ / minkg-1.

\section{MATERIAL \& METHODS}

The study was carried out in the laboratory of HCM State Physical Culture Institute. 31 football players of the first tournament and 33 players of the second league of the Vietnam Championship participated in the study. To assess the readiness of the athletes' function, ECG combination CARDIOLAB has been used.

Physical performance is assessed using PWC170 below load test. The meaning of this test is to determine the power of work that an athlete can perform with a heartbeat of 170 beats per minute. Physical loads are performed on scar gauges in the sitting position. The measuring chair of the scars is placed in such a way that in the lower position of the pedal, the football player's legs are fully straightened in the knee joint. There are two 5-minute downloads each; The interval between breaks is 3 minutes. Calculation of the strength of the first and second loads made taking into account body weight. The first load is selected from calculating $1 \mathrm{~W}(6 \mathrm{~kg} \bullet \mathrm{m} / \mathrm{min})$ for every $1 \mathrm{~kg}$ of body weight, the second $-2 \mathrm{~W}(12 \mathrm{~kg} \bullet \mathrm{m} / \mathrm{min})$ per $1 \mathrm{~kg}$ of body weight

At the end of the first and second loads, the heart rate is recorded. The heart rate at the end of the first load must be $110-120$ beats / minute, at the end of the second - 150160 beats / minute. The difference in heart rate between the first and second load must be 40 beats / minute. If the difference of HR 40 beats per minute is not achieved, after 3 minutes of rest, the third load is performed at a rate of 2.5-3 $\mathrm{W}$ (15-18 kgm / min) per $1 \mathrm{~kg}$ of body weight. In this case, the first and third loads have been taken into account (Pertsukhov A, et al, 2018). Calculation of physical performance indicators is carried out according to the formula:

$\mathrm{PWC}_{170}=\mathrm{N}_{1}+\left(\mathrm{N}_{2}-\mathrm{N}_{1}\right) 170-\mathrm{f}_{1} / \mathrm{f}_{2}-\mathrm{f}_{1}$

Where: PWC - exercise power at a heart rate of 170 beats/minute in $\mathrm{W}$ or $\mathrm{kgm} / \mathrm{min}$;

$\mathrm{N}_{1}$ and $\mathrm{N}_{2}$ - the power of the first and second loads in $\mathrm{W}$ or $\mathrm{kgm} / \mathrm{min}$; $f_{1}$ and $f_{2}$ - the heart rate at the end of the first and second loads.

All the results of the research were processed by the generally accepted methods of mathematical processing of experimental data with the calculation of the arithmetic mean, the standard error of the arithmetic mean, the criterion for the difference in the mean values of the Styudent. Reliability was considered essential at a five percent level of significance.

Methods of mathematical statistics are used in accordance with the known recommendations using computer programs (M.Excel) and (SPSS 20.0).(Dao Chanh Thuc, 2018).

\section{$3 \quad$ RESULTS}

Table 1 presents the indicators of the functional readiness of players of various playing roles of the team of the first league of the championship of Vietnam. It is revealed that the values of some indicators of the functional readiness of players of various gaming specialization are not the same.

Table 1. Indicators of the functional readiness of football players of various playing roles of teams of the first league of Vietnam( $M \pm S D)$

\begin{tabular}{lll}
\hline Gaming Role & $\begin{array}{l}\text { Indicators } \\
\text { VO2max, } \\
\mathrm{ml} / \mathrm{min} \cdot \mathrm{kg}-1\end{array}$ & $\begin{array}{l}\mathrm{PWC} 170, \\
\mathrm{~kg} \cdot \mathrm{m} / \mathrm{min} \cdot \mathrm{kg}\end{array}$ \\
\hline $\begin{array}{l}\text { Goalkeepers }(\mathrm{n}=5) \\
\text { Central defenders } \\
(\mathrm{n}=6)\end{array}$ & $55.74 \pm 1.16$ & $20.01 \pm 0.46$ \\
$\begin{array}{l}\text { Wing defenders } \\
(\mathrm{n}=4)\end{array}$ & $64.71 \pm 1.06$ & $21.45 \pm 0.26$ \\
$\begin{array}{l}\text { Central midfielders } \\
(\mathrm{n}=5)\end{array}$ & $64.83 \pm 0.75$ & $21.53 \pm 0.45$ \\
$\begin{array}{l}\text { Wing midfielders } \\
(\mathrm{n}=6)\end{array}$ & $62.73 \pm 0.95$ & $22.13 \pm 0.25$ \\
$\begin{array}{l}\text { Forwards }(\mathrm{n}=5) \\
\begin{array}{l}\text { On the average for } \\
\text { the group }(\mathrm{n}=31)\end{array}\end{array}$ & $61.86 \pm 0.98$ & $21.71 \pm 0.24$ \\
\hline
\end{tabular}

The analysis of the maximum oxygen consumption (VO2max) of the players of the first league team shows that this indicator was in the range from $55.74 \mathrm{ml} / \mathrm{min} \cdot \mathrm{kg}-1$ to $64.71 \mathrm{ml} / \mathrm{min} \cdot \mathrm{kg}-1$, with an average value of $62.37 \pm 0.98$ $\mathrm{ml} / \mathrm{min} \cdot \mathrm{kg}-1$.

Comparing the indicators of the VO2max of the players of the first league of various playing roles, it can be seen that the highest values of the VO2max are typical for central midfielders $(64.83 \pm 0.75 \mathrm{ml} / \mathrm{min} \cdot \mathrm{kg}-1)$. The lowest indices of VO2max were observed in goalkeepers $(55.74 \pm 1.16$ $\mathrm{ml} / \mathrm{min} \cdot \mathrm{kg}-1)$.

Goalkeepers are significantly inferior to central defenders $(\mathrm{t}=3.86 ; \mathrm{p}<0.01)$, wing defenders $(\mathrm{t}=3.89 ; \mathrm{p}<0.01)$, central midfielders $(\mathrm{t}=4.81 ; \mathrm{p}<0.01)$, the wing midfielders $(\mathrm{t}=3.58$; $\mathrm{p}<0.01)$ and the attacker $(\mathrm{t}=3.01 ; \mathrm{p}<0.05)$. In addition, central midfielders in this indicator significantly exceed the wing midfielders $(\mathrm{t}=2.39 ; \mathrm{p}<0.05)$ and attackers $(\mathrm{t}=3.07$; $\mathrm{p}<0.05$ ). (Dao Chanh Thuc, 2018). 
Analysis of the physical performance (PWC170) of the players of the first league teams of various roles shows that this indicator was in the range from $20.01 \mathrm{~kg} \cdot \mathrm{m} / \mathrm{min} \cdot \mathrm{kg}-1$ to $22.13 \mathrm{~kg} \cdot \mathrm{m} / \mathrm{min} \cdot \mathrm{kg}-1$, with an average value $21.32 \pm 0.34$ $\mathrm{kg} \cdot \mathrm{m} / \mathrm{min} \cdot \mathrm{kg}-1$.

Table 2 presents the indicators of the functional readiness of the players of various roles of the team of the second league of the championship of Vietnam.

Table 2. Indicators of the functional readiness of players of various playing roles of teams of the second league of Vietnam (M $\pm \mathrm{SD})$

\begin{tabular}{lll}
\hline Gaming Role & $\begin{array}{l}\text { Indicators } \\
\text { VO2max, } \\
\mathrm{ml} / \mathrm{min} \cdot \mathrm{kg}-1\end{array}$ & $\begin{array}{l}\text { PWC170, } \\
\mathrm{kg} \cdot \mathrm{m} / \mathrm{min} \cdot \mathrm{kg} \\
-1\end{array}$ \\
\hline $\begin{array}{l}\text { Goalkeepers }(\mathrm{n}=6) \\
\begin{array}{l}\text { Central defenders } \\
(\mathrm{n}=6)\end{array}\end{array}$ & $\begin{array}{l}53.76 \pm 0.68 \\
61.92 \pm 1.22\end{array}$ & $\begin{array}{l}19.96 \pm 0.27 \\
21.02 \pm 0.62\end{array}$ \\
$\begin{array}{l}\text { Wing defenders } \\
(\mathrm{n}=5)\end{array}$ & $65.32 \pm 1.32$ & $21.73 \pm 0.43$ \\
$\begin{array}{l}\text { Central midfielders } \\
(\mathrm{n}=6)\end{array}$ & $63.77 \pm 1.33$ & $23.07 \pm 0.39$ \\
$\begin{array}{l}\text { Wing midfielders } \\
(\mathrm{n}=6)\end{array}$ & $63.27 \pm 1.37$ & $21.65 \pm 0.58$ \\
$\begin{array}{l}\text { Forwards (n=4) } \\
\text { The average for the } \\
\text { group }(\mathrm{n}=33)\end{array}$ & $61.75 \pm 0.71$ & $21.76 \pm 0.35$ \\
\hline
\end{tabular}

The results of the study show that the maximum oxygen consumption (VO2max) for the second league players ranged from $53.76 \mathrm{ml} / \mathrm{min} \cdot \mathrm{kg}-1$ to $65.32 \mathrm{ml} / \mathrm{min} \cdot \mathrm{kg}-1$, with an average value of $61.47 \pm 1.11 \mathrm{ml} / \mathrm{min} \cdot \mathrm{kg}-1$.

At the same time, the highest values of the VO2max among the players of the second league were noted in the wing defenders $(64.32 \pm 1.32 \mathrm{ml} / \mathrm{min} \cdot \mathrm{kg}-1)$, and the smallest - for goalkeepers $(53.76 \pm 0.68 \mathrm{ml} / \mathrm{min} \cdot \mathrm{kg}-1)$.

As a result of the comparative analysis it was found that the goalkeepers are much inferior to the central defenders $(\mathrm{t}=3.79 ; \mathrm{p}<0.01)$, the wing defenders $(\mathrm{t}=5.81 ; \mathrm{p}<0.01)$, central midfielders $(\mathrm{t}=6.02 ; \mathrm{p}<0.01)$, the wing midfielders $(\mathrm{t}=4.56 ; \mathrm{p}<0.01)$ and the attacker $(\mathrm{t}=4.97 ; \mathrm{p}<0.01)$. In turn, the wing defenders in this indicator significantly exceed the players of the attack line $(\mathrm{t}=2.69 ; \mathrm{p}<0.05)$.

Analysis of the physical performance of the players of the teams of the second league shows that the PWC170 for this group of players was in the range from 19.96 $\mathrm{kg} \cdot \mathrm{m} / \mathrm{min} \cdot \mathrm{kg}-1$ to $23.07 \mathrm{~kg} \cdot \mathrm{m} / \mathrm{min} \cdot \mathrm{kg}-1$, with an average value of $21.53 \pm 0.44 \mathrm{~kg} \cdot \mathrm{m} / \mathrm{min} \cdot \mathrm{kg}-1$.

The highest indicators of physical fitness among the players of the second league of Vietnam were registered with the wing defenders $(21.73 \pm 0.43 \mathrm{~kg} \cdot \mathrm{m} / \mathrm{min} \cdot \mathrm{kg}-1)$ and central midfielders $(23.07 \pm 0.39 \mathrm{~kg} \cdot \mathrm{m} / \mathrm{min} \cdot \mathrm{kg}-1)$.

The lowest indicators of physical performance (PWC170) are noted in goalkeepers $(19.96 \pm 0.27 \mathrm{~kg} \cdot \mathrm{m} / \mathrm{min} \cdot \mathrm{kg}-1)$.

Comparative analysis of indicators of physical performance of the players of the second league of various playing roles shows that the goalkeepers in this indicator are significantly inferior to the central midfielders $(\mathrm{t}=2.89 ; \mathrm{p}<0.05)$. At the same time, it should be noted that significant differences in physical performance are characteristic only for the indicators of goalkeepers and field players. There are no significant differences in the performance of PWC170 defenders, midfielders and attackers $(\mathrm{p}>0.05)$.

Table 3 and Table 4 show the average values of the indicators of the functional readiness of the players of the teams of the first and second leagues of the championship of Vietnam. Differences in the level of the investigated parameters among players of various playing roles of teams of various ability are noted.

Table 3. Indicators of maximum oxygen consumption(VO2max) of the players of the teams of the first and second leagues of the championship of Vietnam

\begin{tabular}{lllll}
\hline Game Role & $\begin{array}{l}\text { Football } \\
\text { players of the } \\
\text { first league } \\
(\mathrm{n}=31)\end{array}$ & $\begin{array}{l}\text { Football } \\
\text { players of the } \\
\text { second league } \\
(\mathrm{n}=33)\end{array}$ & $\mathrm{t}$ & $\mathrm{p}$ \\
\hline $\begin{array}{l}\text { Goalkeepers } \\
(\mathrm{n}=3)\end{array}$ & $55.74 \pm 1.16$ & $53.76 \pm 0.68$ & 0.92 & $>0.05$ \\
$\begin{array}{l}\text { Central } \\
\text { defenders } \\
\text { (n=5) }\end{array}$ & $64.71 \pm 1.06$ & $61.92 \pm 1.22$ & 1.18 & $>0.05$ \\
$\begin{array}{l}\text { Wing } \\
\text { defenders } \\
\text { (n=4) }\end{array}$ & $64.32 \pm 1.01$ & $65.32 \pm 1.32$ & 0.27 & $>0.05$ \\
$\begin{array}{l}\text { Central } \\
\text { midfielders } \\
\text { (n=5) }\end{array}$ & $64.83 \pm 0.75$ & $63.77 \pm 1.33$ & 1.23 & $>0.05$ \\
$\begin{array}{l}\text { Wing } \\
\text { midfielders } \\
\text { (n=5) }\end{array}$ & $62.73 \pm 0.95$ & $63.27 \pm 1.37$ & 0.83 & $>0.05$ \\
$\begin{array}{l}\text { Forwards } \\
\text { (n=4) }\end{array}$ & $61.86 \pm 0.98$ & $61.75 \pm 0.71$ & 0.49 & $>0.05$ \\
$\begin{array}{l}\text { On the } \\
\text { average for } \\
\text { the group } \\
\text { (n=33) }\end{array}$ & $62.37 \pm 0.98$ & $61.47 \pm 1.11$ & 1.05 & $>0.05$ \\
\hline
\end{tabular}

Table 4. Physical capacity (PWC170) football players of the first and second league players of championship of Vietnam

\begin{tabular}{lllll}
\hline Game Role & $\begin{array}{l}\text { Football } \\
\text { players of the } \\
\text { first league } \\
(\mathrm{n}=31)\end{array}$ & $\begin{array}{l}\text { Football } \\
\text { players of the } \\
\text { second league } \\
(\mathrm{n}=33)\end{array}$ & $\mathrm{t}$ & $\mathrm{p}$ \\
\hline $\begin{array}{l}\text { Goalkeepers } \\
(\mathrm{n}=3)\end{array}$ & $20.01 \pm 0.46$ & $19.96 \pm 0.27$ & 0.45 & $>0.05$ \\
$\begin{array}{l}\text { Central } \\
\text { defenders } \\
(\mathrm{n}=5)\end{array}$ & $21.45 \pm 0.26$ & $21.02 \pm 0.62$ & 0.43 & $>0.05$ \\
$\begin{array}{l}\text { Wing } \\
\text { defenders } \\
(\mathrm{n}=4)\end{array}$ & $21.53 \pm 0.45$ & $21.73 \pm 0.43$ & 0.37 & $>0.05$ \\
$\begin{array}{l}\text { Central } \\
\text { midfielders } \\
(\mathrm{n}=5)\end{array}$ & $22.13 \pm 0.25$ & $23.07 \pm 0.39$ & 0.61 & $>0.05$ \\
$\begin{array}{l}\text { Wing } \\
\text { midfielders } \\
(\mathrm{n}=5)\end{array}$ & $21.71 \pm 0.24$ & $21.65 \pm 0.58$ & 0.35 & $>0.05$ \\
$\begin{array}{l}\text { Forwards } \\
(\mathrm{n}=4)\end{array}$ & $21.06 \pm 0.38$ & $21.76 \pm 0.35$ & 0.61 & $>0.05$ \\
$\begin{array}{l}\text { On the } \\
\text { average for } \\
\text { the group } \\
(\mathrm{n}=33)\end{array}$ & $21.32 \pm 0.34$ & $21.53 \pm 0.44$ & 0.70 & $>0.05$ \\
\hline
\end{tabular}




\section{DISCUSSION \& CONCLUSIONS}

This study continues some of the work devoted to the study of the functional preparation of football players of different ages and abilities (Ordzhonikidze, et al., 2007; Shamardin, et al., 2008 ; Shamardin, 2012).

The data obtained partly confirm the results of other studies (Pertsukhov A, et al, 2018), in which the author believes that the success of football teams is guaranteed, first of all, by careful preparation High technique and tactics of football players, and only then with aerobic ability. This situation is explained by the fact that in football, special qualities and abilities are leading (Pertsukhov A, et al, 2018). However, according to us, there is a minimum level of aerobic ability, under which a professional football player does not have the right to go down.

The research conducted allowed to determine that the minimum value of the player's maximum oxygen consumption was about $60 \mathrm{ml} / \mathrm{min} \bullet \mathrm{kg}-1$. This assumption was confirmed in their work by the Other experts (Godick, 2006), people in laboratories and field conditions have tested football players - experts, semi-professionals and amateurs.

This study adds and extends data on the player's functional readiness to different role players. Therefore, many authors (Shamardin, 2012) note that indicators of maximum oxygen consumption (VO2max) and physical performance (PWC170) for players of different roles are not the same. Differences in the data obtained can be explained by the features of the activity in competitive operating conditions and the load characteristics in the training activities of the players have different roles.

In this regard, it can be assumed that the difference in training volume for players with different roles not only contributes to improved functional readiness according to the role structure of the role, but It also ensures to improve the quality of game activity for each individual player and the entire team (Pertsukhov A, et al, 2018).

Most researchers believe that the level of VO2max can grow during the season, with the release of it to the maximum value to the end (Casajus, 2001). However, in some cases, teams had a decline in VO2max indicators at the end of the season (Drust, et al, 2000). Such differences can be explained by the fact that the players of many teams end the season in a state of strong physical fatigue, which determines the decline in physiological parameters of movement. tablets.

Prospects of further studies The next study will be devoted to the study of the dynamics of the indicators VO2max and PWC170 of the players of the second team and the first tournament of Vietnam in stages. Different of the annual training cycle.

The results of this study show that the greatest level of aerobic performance is characteristic of wing players and midfield players. So, according to our data, the VO2max indicators of central midfielders range from 63.77 to 64.83 $\mathrm{ml} / \mathrm{min} \mathrm{kg}-1$. But, especially important is aerobic performance for the flank, or, the wing players who perform the greatest amount of work on the field. It has been established that the VO2max of wing defenders is in the range from 64.32 to $65.32 \mathrm{ml} / \mathrm{min} \mathrm{kg}-1$. Low aerobic performance is observed in goalkeepers $(53.76-55.74 \mathrm{ml} / \mathrm{min} \mathrm{kg}-1)$, as this type of their activity is not determinative.

According to the data received, the average level of the VO2max for professional football players is $63.8 \pm 0.5 \mathrm{ml} / \mathrm{min} \bullet \mathrm{kg}-1$ (Pertsukhov A, et al, 2018). Attention is drawn to the fact that according to the indicators studied - the VO2max and PWC170 - there were no differences between the players of the teams of the first and second leagues of the championship of Vietnam. This means that the aerobic abilities of players of various skills are the same.

\section{REFERENCES}

[1] Casajus JA. Seasonal variation in fitness variables in professional soccer players. J Sports Med PhysFitness. 2001;41(4):9-463.

[2] Measurement in sports. Dao Chanh Thuc. 2018;.

[3] Physiological responses to laboratory-based soccer-specific intermittent and continuous exercise. J Sports Sci. 2000;p. 92-885.

[4] Francis T, editor. Gender differences in strength and endurance of elite soccer players. Science and football; 2002.

[5] Ordzhonikidze ZG, Pavlov VI. Physiology of football. Human Being, Olympia. 2008;p. 240.

[6] G PZ, I VV, I DN, E A. The state of functional readiness sportsmen in line up of leading teams of Russia. Physiology of. 2007;man.:114-118.

[7] V SV, S Z, V K, S K. preparedness of football players with different qualifications. Pertsukhov A, Perevoznick. 2018;18(2). $710-714$.

[8] Platonov VN. Adaptation in sport. Zdorov'e. 1988;21.

[9] Shamardin AA, Godik MA, Shamardin AI, Solopov IN. Functional training of junior football players on the basis block-module technology. Science notes, 12; 2008.

[10] Shamardin VN. Technology of preparedness of elite football team. Innovation; 2012.

[11] Stroyer I, Hansen L, Hansen K. Physiological profile and activity pattern of young soccer players during match play. Med Sci Sports Exerc. 2004;36(1):74-168.

[12] Tamlin DL. The relationship between aerobic fitness and recovery from high intensity exercise. Sports Med. 2001;31(1):1-11.

[13] Tyulenkov SU. Theory-methodical approaches to the management system of training of football players of high qualification. Physical culture, 352 c; 2007.

\section{AUTHOR BIOGRAPHY}

Dao Chanh Thuc Physical Education Department, An Giang University, VIET NAM 